\title{
Insights into novel anticancer applications for apigenin
}

\author{
Adam Kowalczyk ${ }^{1, A-F}$, Agnieszka Bodalska ${ }^{2, C, D}$, Marta Miranowicz ${ }^{3, C, D}$, Katarzyna Karłowicz-Bodalska ${ }^{4, C, D}$ \\ ${ }^{1}$ Department of Pharmacognosy, Wroclaw Medical University, Poland \\ 2 Students' Pharmacognosy Society, Wroclaw Medical University, Poland \\ ${ }^{3}$ Students' Industrial Pharmacy Society, Wroclaw Medical University, Poland \\ ${ }^{4}$ Department of Industrial Pharmacy, Wroclaw Medical University, Poland \\ A - research concept and design; B - collection and/or assembly of data; $C$ - data analysis and interpretation; \\ $D$ - writing the article; $E$ - critical revision of the article; $F$ - final approval of article
}

Address for correspondence

Adam Kowalczyk

E-mail:adam.kowalczyk@umed.wroc.pl

Funding sources

None declared

\section{Conflict of interest}

None declared

Received on March 13, 2015

Revised on March 28, 2015

Accepted on April 24, 2015

\begin{abstract}
Flavonoids, naturally occuring derivatives of 2-phenyl-benzo- $\gamma$-pyrone, are widespread in plants as coloring substances. Apigenin (4,5,7,-trihydroxyflavone (5,7-dihydroxy-2-(4-hydroxyphenyl)-4H-1-benzopyran-4-one), molecular formula $\mathrm{C}_{15} \mathrm{H}_{10} \mathrm{O}^{5}$, is a flavonoid present in many fruits and vegetables, primarily in citrus fruits, apples, parsley and celery leaves. It is also found in some medicinal plants, including chamomile flowers, thyme, oregano, peppermint, lemon balm and yarrow, as a 7-0-glycoside with anti-inflammatory and antioxidant activity. In recent years it has attracted a great deal of interest as a bioactive substance reported to have anticancer properties. According to recent literature data, apigenin is able to reduce cancer cell glucose uptake, inhibit remodeling of the extracellular matrix, inhibit cell adhesion molecules that participate in cancer progression and hinder the development of blood vessels needed by growing tumors. It is reported to protect against a wide variety of cancers. The mechanism of anticancer activity is still under investigation and further research is needed.
\end{abstract}

Key words: flavonoids, apigenin, anticancer agent, chemoprevention

DOI

10.17219/acem/41978

\section{Copyright}

Copyright by Author(s)

This is an article distributed under the terms of the

Creative Commons Attribution Non-Commercial License

(http://creativecommons.org/licenses/by-nc-nd/4.0/) 
In recent years there have been many publications revealing the great importance of numerous natural substances as dietary components that have beneficial activity in many diseases of the gastrointestinal tract. Among them are derivatives of phenylchromone, the flavonoids, which exist in nature either as free aglycones or glycosides. Flavonoids have attracted a great deal of scientific and public attention because they are the most common group of plant secondary metabolites present in the human diet. ${ }^{1}$ Flavonoids possess a remarkable spectrum of biological and pharmacological activity, including antioxidant, antiallergic, antibacterial, antimutagenic, antiangiogenic and anticancer activity. ${ }^{2-6}$ On the molecular level they have been reported to possess properties that modulate different enzyme and receptor activities involved in inflammatory pathologies and cancer., ${ }^{7,8} \mathrm{Mul}-$ tiple molecular mechanisms of flavonoids, particularly those inhibiting the promotion and progression of cancer cells, have been tested in recent years in the treatment of different types of cancer. ${ }^{7-9}$ Some of the tested compounds - quercetin, genistein and flavopiridol (synthetic flavonoid) - have entered the late phase of clinical trials for several oncological diseases. ${ }^{10-12}$ Recently apigenin - 4,5,7,-trihydroxyflavone - and its 7-O-glycoside have attracted particular scientific interest as a promising component in cancer therapy. ${ }^{13}$ The bioactive flavonoid apigenin has been found in many fruits, vegetables and medicinal herbs, especially in parsley leaves and chamomile flowers. Apigenin occurs in nature along with its glycosides; the apigenin 7-O-glucoside is their basic compound. Another natural derivative of apigenin used in medicine is vitexin (apigenin 8-C-glucoside), which belongs to the subclass C-glycosyl-flavonoids. In vitexin, glucose residue is attached directly to C-8 of apigenin, without an oxygen atom. Vitexin and its 4'-glucoside are used in cardiology to improve coronary blood flow. ${ }^{1}$ Apart from its various known pharmacological activities, apigenin has been shown to possess a variety of biological properties, including antioxidant, antiproliferative, chemopreventive and anticancer activities. ${ }^{2-6,14}$ Epidemiologic studies suggest that a diet rich in flavones, particularly in apigenin, is related to a decreased risk of certain cancers (of the breast, digestive tract, skin, prostate and some hematological malignancies) and provide strong evidence for a protective role of flavonoids against some malignant neoplasms..$^{15}$ As noted above, apigenin is present in dietary sources, mostly as a 7-glucoside, which is hydrolyzed in the gastrointestinal lumen to be absorbed and distributed as apigenin itself. The epithelium of the gastrointestinal tract is thus exposed to higher concentrations of apigenin than other tissues. ${ }^{1}$ As Lefort and Blay wrote: "Apigenin is able to reduce cancer cell glucose uptake, inhibit remodeling of the extracellular matrix [and] inhibit cell adhesion molecules that participate in cancer progression." ${ }^{1}$

\section{Modification of the cell cycle}

In order to identify the mechanisms of apigenin's activity on the development of the early stages of carcinogenesis and to explain some divergences of reported results, thorough investigations of cell growth and survival, the modulation of angiogenesis and the actions of apigenin on cellular invasion, adhesion and migration were conducted. It has been found that apigenin can inhibit the cell division cycle at different stages. Research has shown that in human tongue squamous carcinoma (SCC-9) and human esophageal cancer (both KYSE-510 and OE33), after exposure to apigenin, the level of cells in the G1 phase (when the cells grow in size and mRNA and high amounts of protein are synthesized) decreased, while the level of cells in the third stage of interphase (the G2 phase) increased. ${ }^{16}$ This is associated with the down-regulation of protein cyclin B1 and the up-regulation of p53-inducible gene 3 and protein p21-WAF1. P21-WAF1 is responsible for G1 phase arrest and the G2/M checkpoint, and apigenin in concentration levels higher than $30 \mu \mathrm{M}$ increases the transcription of this protein. Apigenin can also arrest the cell cycle in the DNA synthetic phase (S-phase). This action was shown in a gastric cancer cell line (SGC-7901). ${ }^{1}$

\section{Apoptosis and angiogenesis}

The natural process of apoptosis (programmed cell death) can be enhanced by apigenin in different ways. ${ }^{17}$ Besides induction of $\mathrm{p} 21 / \mathrm{WAF} 1$ protein (which is also involved in the cell division cycle), apigenin also leads to changes in the phosphorylation of p53 tumor suppressor protein, induction of the nonsteroidal anti-inflammatory drug-activated gene (a growth factor involved in anti-tumorigenesis) and caspase-3 activity. ${ }^{18,19}$ Another way in which this flavonoid promotes programmed cell death is through the modification of the $\mathrm{Bax} / \mathrm{Bcl}-2$ protein ratio and the release of cytochrome $\mathrm{C}$ to the cytoplasm, which binds apoptotic protease activating factor- $1 .{ }^{1}$ Angiogenesis is a process that provides oxygen and nutrients to a growing tumor through the development of a supportive vascular network. It is made possible by pro-angiogenic molecules, among which vascular endothelial growth factor (VEGF) is the primary regulator. VEGF is rate-limited in pathological angiogenesis. ${ }^{1}$ It acts by binding to the VEGF receptor 2 on endothelial cells, finally causing their migration. Research has shown that VEGF receptor expression increases as a tumor becomes more invasive and aggressive. ${ }^{20,21}$ Modest exposure to apigenin (up to $20 \mu \mathrm{M}$ ) inhibits VEGF promoter activity, causing impaired VEGF signaling which decreases the capacity of tumor cells to migrate. This action of apigenin has been found in gastrointestinal, breast and prostate cancer cells, as well as in hepatocellular carcinoma. ${ }^{20,21}$ 


\section{Inhibition of GLUT-1 expression}

Cancer cells adapt to their tumor microenvironment to utilize nutritional energy sources better; one way this happens is through overexpression of glucose transporters (GLUT), which helps transport glucose into the cell. Apigenin possesses the ability to downregulate the GLUT-1 transporter, therefore inhibiting glucose transport. ${ }^{16,22,23}$

\section{ECM degradation}

There is a group of enzymes that participates in the digestion of components of the extracellular matrix (ECM). This group includes a proteolytic enzyme family - matrix metaloproteinases (MMPs), the main proteolytic enzymes in tumor invasion - which allows cancer cells to degrade the ECM, penetrate the basement membrane and move to other regions. MMPs also regulate cellular adhesion, making it easier for cancer to migrate. ${ }^{1}$ Tumor invasion is connected with the tissue inhibitors of matrix metaloproteinases (TIMPs), which regulate the expression and activity of MMPs. Flavonoids, including apigenin, may inhibit cell migration by having a considerable impact on matrix metaloproteinases activity. ${ }^{1,24}$

\section{Impact on cell adhesion molecules}

Cell adhesion molecules (CAMs) are proteins that play a significant part in binding cells to other cells or surfaces (such as the extracellular matrix). CAMs include four groups: cadherins, integrins, selectins (calcium-dependent) and the immunoglobulin superfamily (calcium independent). Lost or decreased cadherin expression is observed in some epithelial cancers. This process increases movement and invasion in these cells. Apigenin can heighten the expression of cadherin and in this way can suppress tumor formation. ${ }^{23,24}$ The expression of vascular cell adhesion molecules (VCAM) is also modulated by apigenin. Researchers have shown that intraperitoneal injections of this flavonoid decrease the amount of VCAM on endothelial cells of lung capillaries, demonstrating that apigenin can resist tumor metastasis. ${ }^{25}$ Integrins are responsible not only for adhesion to the extracellular matrix, but also for cellular shape, motility and gene transcription. The activation of these proteins can induce downstream signaling events, which recruit and trigger kinases, e.g. focal adhesion kinase (FAK). ${ }^{26}$ Overexpression of this kinase promotes invasion and is observed in many tumor cells. Apigenin reduces FAK expression and phosphorylation, and also induces its degradation. ${ }^{27,28}$ Chemokines - chemotactic cytokines - are small signaling proteins. There are 2 important components that are involved in the metastasis of colon and pancreatic cancer: CXCR4 chemokine receptor type 4 and its ligand, stro- mal-derived-factor-1 (CXCL12). Activation of the receptor activates molecules essential for chemotaxis, tumor resistance, growth and gene transcription. ${ }^{29,30}$ High CXCR4 expression results in the spread and relapse of the tumor, and also a poor prognosis because of its association with proliferation, motility and enhanced VEGF release. ${ }^{31,32}$ Another receptor that responds to CXCL12 is C-C chemokine receptor type 7 (CXCR7). ${ }^{33}$ The induction of CXCR7 and CXCR4 activating pathways depends on cluster of differentiation 26 (CD26). ${ }^{34}$ This enzyme suppresses CXCL12's ability to promote the metastasis and progression of the tumor. Apigenin enhances the expression of CD26 in tumor cells, where it is often lowered. ${ }^{35}$

Other anti-cancer properties of apigenin include scavenging free radicals, inhibiting ornithine decarboxylase (an important factor in tumor growth) and enhancing the concentration of glutathione, which is important for reducing oxidative stress. ${ }^{1,7,14}$ Apigenin is well known as an inhibitor of kinase $\mathrm{C}$, mitogen-activated protein kinase (MAPK) and other kinases. Research has shown that a reduction of MAPK leads to the inhibition of cell proliferation in human prostate cancer and apoptosis in anaplastic thyroid cancer. ${ }^{36}$ Apigenin can also lower the concentrations of the enzymes aromatase and 17b-hydroxysteroid dehydrogenase. Breast and prostate cancer growth is inhibited by the influence of apigenin on estrogen receptor $b-1 .{ }^{37}$

\section{Reducing oxidative DNA damage}

The process of carcinogenesis is closely connected to oxidative DNA damage by free radicals, reflected by levels of 8-hydroxy-2 deoxyguanosine (8-OHdG), which results from oxidative modification of guanine. Incorporated into DNA, 8-OHdG leads to point mutation via an adenine and thymine substitution. High accumulations of 8-OHdG in tissues are observed when there is strong DNA damage. Studies have shown that apigenin reduces this damage by protecting cells from oxidative-mediated cellular injury, due to decreased levels of 8-OHdG in $\mathrm{H}_{2} \mathrm{O}_{2}$-treated cells exposed to apigenin. This flavone is incorporated into the nuclear matrix, where it binds to nucleic acid bases. This has been observed in prostate cancer cells. ${ }^{38}$

\section{Differentiation-induction effect}

"Differentiation therapy" is the concept of treating leukemia by forcing the malignant cells to undergo terminal differentiation instead of inducting cell death. ${ }^{36}$ It plays an important role in hematological cancer where cell differentiation is inhibited at a particular stage in its maturation. Flavonoid apigenin-7-glucoside can induce acute myeloid leukemia HL-60 cells and chronic myeloid leukemia K562 cells to differentiate the granulocytic 
and the erythrocytic lineages, which is possible because apigenin increases the expression of alfa and gamma hemoglobin genes. Studies have shown that this activity may come from a free hydroxyl group at the C-4. position. ${ }^{39}$

\section{Conclusions}

Apigenin is a non-toxic dietary flavonoid naturally occurring in plants, vegetables and fruit. It has been known for many years as an antioxidant and anti-inflammatory agent. Recent studies have shown promising new possibilities for apigenin's anticancer activity. It protects and counteracts a wide variety of cancers, with high selectivity for cancer cells as opposed to non-cancerous cells. The mechanism of its action is still under investigation and further research is needed.

\section{References}

1. Lefort ÉC, Blay J. Apigenin and its impact on gastrointestinal cancers. Mol Nutr Food Res. 2013;57:126-144.

2. Andersen $\varnothing$, Markham KR. Flawonoids: Chemistry, Biochemistry and Applications. New York, NY: Taylor \& Francis Group; 2006:219-220.

3. Cushnie TPT, Lamb AJ. Recent advances in understanding the antibacterial properties of flavonoids. Int J Antimicrob Agents. 2011;38:99-107.

4. García-Lafuente A, Gullamón E, Villares A, Rostagno MA, Martínez JA. Flawonoids as anti-inflammatory agents: Implications in cancer and cardiovascular disease. Inflamm Res. 2009;58:537-552.

5. Kawai M, Hirano T, Higa S, et al. Flawonoids and related compounds as anti-allergic substances. Allergol Int. 2007;56:113-123.

6. Li AN, Li S, Zhang YJ, Xu XR, Chen YM, Li HB. Resources and biological activities of natural polyphenols. Nutrients. 2014;6:6020-6047.

7. Ravishankar D, Rajora AK, Greco F, Osborn HMI. Flawonoids as prospective compounds for anti-cancer therapy. Int J Biochem Cell Biol. 2013;45:2821-2831.

8. Lazarevic B, Boezelijn G, Diep LM, et al. Efficacy and safety of short-term genistein intervention in patients with localized prostate cancer prior to radical prostatectomy: A randomized, placebo-controlled, double-blind phase 2 clinical trial. Nutr Cancer. 2011;63:889-898.

9. Beesley AH, Stirnweiss A, Ferrari E, et al. Comparative drug screening in NUT midline carcinoma. Br J Cancer. 2014;110:1189-1198.

10. Anita S, Manjul PS, Roshan P, Neelam D, Gulzar A. Bio-flavonoid quercetin in oncology. J Pharm Res. 2010;3:2834-2835.

11. Yakisich JS, Ohlsson Lindblom I, Siden A, Cruz MH. Rapid inhibition of ongoing DNA synthesis in human glioma tissue by genistein. Oncol Rep. 2009;22:569-574.

12. Lin TS, Ruppert AS, Johnson AJ, et al. Phase II study of flavopiridol in relapsed chronic lymphocytic leukemia demonstrating high response rates in genetically high-risk disease. J Clin Oncol. 2009;27:6012-6018.

13. Sak K. Cytotoxicity of dietary flavonoids on different human cancer types. Pharmacogn Rev. 2014;8:122-146.

14. Sharma H, Kanwal R, Bhaskaran N, Gupta S. Plant flavone apigenin binds to nucleic acid bases and reduces oxidative DNA damage in prostate epithelial cells. PLoS One. 2014;9(3):e91588.

15. Liu HL, Jiang WB, Xie MX. Flawonoids: Recent advances as anticancer drugs. Recent Pat Anticancer Drug Discov. 2010;5:152-164.

16. Melstrom LG, Salabat MR, Ding XZ, et al. Apigenin inhibits the GLUT-1 glucose transporter and the phosphoinositide 3-kinase/Akt pathway in human pancreatic cancer cells. Pancreas. 2008:37;426-431.

17. Walle T, Ta N, Kawamori T, Wen X, Tsuji PA, Walle UK. Cancer chemopreventive properties of orally bioavailable flavonoids: Methylated versus unmethylated flavones. Biochem Pharmacol. 2007;73:1288-1296.
18. Turktekin M, Konac E, Onen HI, Alp E, Yilmaz A, Menevese S. Evaluation of the effects of the flavonoid apigenin on apoptotic pathway gene expression on the colon cancer cell line (HT29). J Med Food. 2011;14:1107-1117.

19. King JC, Lu QY, Li G, et al. Evidence for activation of mutated p53 by apigenin in human pancreatic cancer. Biochim Biophys Acta. 2012;1823:539-604.

20. Zhong Y, Krisanapun C, Lee SH, et al. Molecular targets of apigenin in colorectal cancer cells: Involvement of p21, NAG-1 and p53. Eur J Cancer. 2010;46:3365-3374.

21. Fang J, Zhou Q, Liu LZ, et al. Apigenin inhibits tumor angiogenesis through decreasing HIF-1alpha and VEGF expression. Carcinogenesis. 2007;28:858-864.

22. Kim BR, Jeon YK, Nam MJ. A mechanism of apigenin-induced apoptosis in potentially related to anti-angiogenesis and anti-migration in human hepatocellular carcinoma cells. Food Chem Toxicol. 2011;49:1626-1632.

23. Melstrom LG, Salabat MR, Ding XZ, et al. Apigenin down-regulates the hypoxia response genes: HIF-1alpha, GLUT-1 and VEGF in human pancreatic cancer cells. J Surg Res. 2011;167:173-181.

24. Makrilia N, Kollias A, Manolopoulos L, Syrigos K. Cell adhesion molecules: Role and clinical significance in cancer. Cancer Invest. 2009;27:1023-1037.

25. Shukla S, MacLennan GT, Flask CA, et al. Blockade of beta-catenin signaling by plant flavonoid apigenin suppresses prostate carcinogenesis in TRAMP mice. Cancer Res. 2007:67:6925-6935.

26. Piantelli $M$, Rossi C, lezzi $M$, et al. Flavonoids inhibit melanoma lung metastasis by impairing tumor cells endothelium interactions. J Cell Physiol. 2006;207:23-29.

27. Hehlgans S, Haase M, Cordes N. Signalling via integrins: Implications for cell survival and anticancer strategies. Biochim Biophys Acta. 2007:1775:163-180.

28. Hu XW, Meng D, Fang J. Apigenin inhibited imgration and invasion of human ovarian cancer A2780 cells through focal adhesion kinase. Carcinogenesis. 2008;29:2369-2376.

29. Franzen CA, Amargo E, Todorovic V, et al. The chemopreventive bioflavonoid apigenin inhibits prostate cancer cell motility through the focal adhesion kinase/Src signaling mechanism. Cancer Prev Res. 2009;2:830-841.

30. Matsusue R, Kubo H, Hisamori S, et al. Hepatic stellate cells promote liver metastasis of colon cancer cells by the action of SDF-1/ CXCR4 axis. Ann Surg Oncol. 2009;16:2645-2653.

31. Koshiba T, Hosotani R, Miyamoto Y, et al. Expression of the stromal cell-derived factor 1 and CXCR4 ligand receptor system in pancreatic cancer: A possible role for tumor progression. Clin Cancer Res. 2010;6:3530-3535.

32. Mongan JP, Fadul CE, Cole BF, et al. Brain metastases from colorectal cancer: Risk factors, incidence and the possible role of chemokines. Clin Colorectal Cancer. 2009;8:100-105.

33. Ottaiano A, Franco R, Aiello Talamanca A, et al. Overexpression of both CXC chemokine receptor 4 and vascular endothelial growth factor proteins predicts early distant relapse in stage II-III colorectal cancer patients. Clin Cancer Res. 2006:12;2795-2803.

34. Luker KE, Lewin SA, Mihalko LA, et al. Scavenging of CXCL12 by CXCR7 promotes tumor growth and metastasis of CSCR4-positive breast cancer cells. Oncogene. 2012;31:4750-4758.

35. Liu Z, Christensson M, Forslow A, De Meester I, Sundgvist KG. A CD26-controlled cell surface cascade for regulation of $T$ cell motility and chemokine signals. J Immunol. 2009;183:3626-3624.

36. Lefort EC, Blay J. The dietary flavonoid apigenin enhances the activities of the anti-metastatic protein CD26 on human colon carcinoma cells. Clin Exp Metastasis. 2011;28:337-349.

37. Cheung ZH, Leung MC, Yip HK, Wu W, Siu FK, So KF. A neuroprotective herbal mixture inhibits caspase-3-independent apoptosis in retinal ganglion cells. Cell Mol Neurobiol. 2008;28:137-155.

38. Shukla S, Gupta S. Apigenin: A promising molecule for cancer prevention. Pharm Res. 2010;27:962-978.

39. Isoda H, Motojima H, Onaga S, Samet I, Villareal MO, Han J. Analysis of the erythroid differentiation effect of flavonoid apigenin on K562 human chronic leukemia cells. Chem Biol Interact. 2014;220:269-277. 